\title{
Endoscopic corpus callosotomy: an animal study
}

\author{
R. Shane Tubbs ${ }^{1}$, Matthew D. Smyth ${ }^{2}$, George Salter ${ }^{1}$, Jeffrey P. Blount ${ }^{2}$ \\ ${ }^{1}$ Department of Cell Biology, University of Alabama at Birmingham U.S.A. \\ 2 Department of Pediatric Neurosurgery, Children's Hospital, Birmingham, Alabama U.S.A.
}

\begin{abstract}
We have previously described a technique for the partial bisection of the corpus callosum in the cadaver in order to increase the minimally invasiveness of this procedure. We now present our experience with this procedure in an animal model. Following a $1.0 \mathrm{~cm}$ midline skin incision, cranial trephinations (approximately $0.5 \mathrm{~cm}$ ) were performed in five adult pigs under general endotracheal anesthesia. A rigid endoscope (AESCULAP, Tuttlingen, Germany) was next introduced and used to transect the approximate anterior two-thirds of the corpus callosum. Following the procedure, brains were observed for gross injury to vascularities or non callosal nervous tissue. No vascular complications were encountered in any of our animal specimens (e.g. superior sagittal sinus, anterior cerebral, frontopolar, or pericallosal arteries). The corpus callosum was easily transected in each specimen. All animals survived the procedure. We believe this technique could provide a less invasive mechanism for patients primarily children, who require corpus callosotomy and will minimize much of the morbidity associated with the traditional methods of sectioning the corpus callosum. Human studies are now necessary to confirm our findings. ( $J$ Pediatr Neurol 2003; 1(1): 25-28).
\end{abstract}

Key words: minimally invasive, epilepsy, seizure, surgery.

Correspondence: R. Shane Tubbs, Ph.D.,

Pediatric Neurosurgery 1600 7th Avenue South Acc 400

Birmingham, Alabama 35233 U.S.A.

Tel: 205-939-9914, fax: 205-939-9972.

E-mail: richard.tubbs@ccc.uab.edu

Received: January 22, 2003.

Revised: February 5, 2003.

Accepted: February 7, 2003.

\section{Introduction}

Despite the recent progress in understanding the etiology of epilepsy, an extensive arsenal of medications fails to provide satisfactory seizure control in $30-40 \%$ of epileptic patients (1). In the United States, there are at least 300,000 people with medically refractory seizures of partial onset (1). Refinements in operative technique are essential for decreasing the morbidity associated with neurosurgical procedures that are used to treat epilepsy patients that are refractory to medical therapy. These include procedures such as hemispherectomy and corpus callosotomy. Minimally invasive approaches to the anterior cranial fossa have been and are currently used (25). Of these, many have utilized a brow incision for access to the anterior cranial fossa $(3,4)$. Some have also used endoscopy with these minimally invasive brow procedures $(5,6)$. Patients suffering from epilepsy who are treated with corpus callosotomy have traditionally undergone open craniotomy with sectioning of all or portions of the corpus callosum. Other than the recent use of a stereotactic imageguided system (7), corpus callosotomy, which is not performed as often as in the past, is today done in much the same manner as it was at its inception. We have developed a new technique that uses a minimally invasive brow incision with a supraorbital trephination that allows the introduction of an endoscope inter-hemispherically therefore allowing for transection of the corpus callosum (8). We now describe our findings in a live animal model. Our hopes are that this novel technique will be of use to the neurosurgeon that performs epilepsy surgery especially in pediatric patients in which the frontal sinus is underdeveloped.

\section{Materials and Methods}

Five adult male pigs were used for this study. Prior to the initiation of this study, approval was received from the Institutional Animal Care and Use Committee at the University of Alabama at Birmingham. All pigs were anesthetized by 


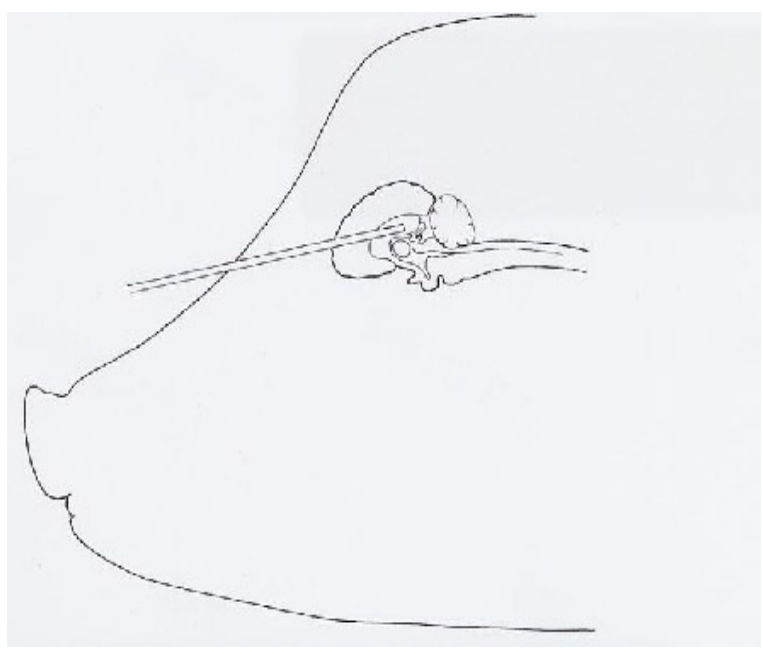

Figure 1. Drawing illustrating the trajectory of the endoscope in the pig.

intravenous thiopental ( $25 \mathrm{mg} / \mathrm{kg}$ body weight) and following intubation, anesthesia was maintained by isoflurane in $100 \%$ oxygen (Ohio Vaporizer, Madison, WI, USA) End-tidal isoflurane concentrations were maintained at approximately $0.3 \%$. A continuous infusion of intravenous fentanyl (0.2-2.0 $\mathrm{mg} / \mathrm{kg}$ ) was administered throughout the experiment. Anesthesia was assured by monitoring changes in systemic arterial pressure and blood pressure during a strong hoof pinch. Lactated Ringer's solution was infused at a rate of 5-10 ml/kg body weight/hour via the left femoral vein and the pigs were mechanically ventilated (Ohio Anesthesia Ventilator, Madison, WI, USA), and arterial carbon dioxide was maintained within the normal physiological range. Blood $\mathrm{pH}$ was maintained between 7.3 and 7.45 and body temperature was maintained between 37 and $39{ }^{\circ} \mathrm{C}$. Animals were next placed in the supine position with the head elevated to $45^{\circ}$. No intracranial pathology was noted during our procedure in any of the eight specimens. A $1.0 \mathrm{~cm}$ midline skin incision was performed beginning at approximately the glabella. A small retractor was next positioned and a hand twist drill was next used to place an approximately $0.5 \mathrm{~cm}$ diameter hole near the midline $2.0 \mathrm{~cm}$ superior to the base of the snout. The dura mater was next incised with a \#15 scalpel blade to create an approximate 0.5 linear opening. A zero degree rigid pediatric endoscope (AESCULAP, Tuttlingen, Germany) with double working ports was introduced through the dura (just lateral to the midline to avoid the most anterior portion of the superior sagittal sinus) and between the falx cerebri and left frontal lobe (Figure 1). A self retaining holder for the endoscope was not used for this procedure. A course between the falx cerebri and left frontal lobe received from the Institutional Animal Care and Use Committee at the University of Alabama at was arbitrarily chosen.

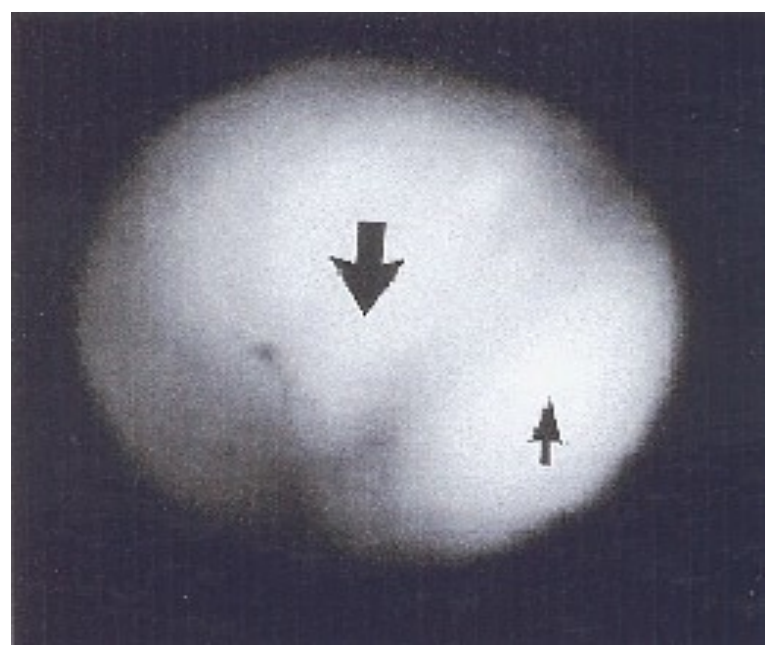

Figure 2. Endoscopic view of the genu of the corpus callosum (small arrow) and the A2 segment of the anterior cerebral artery (large arrow).

Care was taken as to not injure the anterior cerebral artery or its branches (Figure 2). Following the identification of the genu of the corpus callosum, blunt dissection via the tip of the endoscope was performed posteriorly until approximately the anterior two-thirds were traversed. Care was taken to stay beneath the indusium griseum superiorly so as to avoid the pericallosal branches of the anterior cerebral artery. Following each procedure, the brains were harvested and the corpus callosum examined for extent of dissection and surrounding trauma.

\section{Results}

All callosal dissections of the corpus callosum were easily performed without obvious injury to vasculature or non callosal nervous tissue. No frontal sinuses were encountered in any animal. The angulation of the endoscope could easily be adjusted superiorly and inferiorly so as to manipulate both the genu and rostrum of the corpus callosum. Occasionally, when the tip of the endoscope was used for corpus callosum dissection, withdrawal of the endoscope was necessary in order to clean the lens of the scope. After removal of the brains, it was noted that all specimens had at least the anterior two-thirds of the corpus callosum transected. Three specimens had separation of the proximal splenium.

\section{Discussion}

In 1940, Van Wagenen and Herren (9) first reported the technique of dividing the corpus callosum for severe generalized seizures. In addition to this sectioning, the interthalamic adhesion, anterior commissure, and one fornix were also divided. 
Widely accepted indications for corpus callosotomy include medically intractable tonic or atonic seizures with frequent falls and injuries and patients with generalized tonic-clonic seizures (10-12). Traditional neurosurgical methods of callosotomy must be performed carefully in order to avoid the superior sagittal sinus, cortical draining veins, branches of the anterior cerebral artery, and over retraction of the cerebral hemispheres (13). In an attempt to be more minimally invasive, we have developed a potential technique for callosotomy using a brow incision and then performing a small trephination of the frontal bone (8). This procedure is next followed by the introduction of an endoscope interhemispherically which can then be used to bisect the corpus callosum in a parasagittal manner. In neurosurgery, supraorbital craniotomies are often utilized for access to the anterior cranial fossa and sellar region (2-4,9). In 1995, Cohen et al. (6) described a technique in which small supraorbital craniotomies were performed in cadavers and an endoscope introduced intracranially in order to visualize the rostral brain stem. Menovsky et al. (5) have since used the technique of Cohen et al. (6) in operations involving the interpeduncular fossa with good success.

Our human cadaveric method utilized a more medial bony opening through the frontal bone at a level approximately $1.0 \mathrm{~cm}$ superior to the glabella (8). The dura mater could be opened relatively safely without endangering the superior sagittal sinus which is very small in its anterior third and usually does not begin until the level of the foramen caecum at which point its diameter is approximately only $2.0 \mathrm{~mm}(14,15)$. Browder has found the small anterior beginning of the superior sagittal sinus to be commonly several millimeters to a few centimeters posterior to the foramen caecum (14). Our technique would also be performed preferably in small children in whom the frontal sinus has yet to fully develop. If however a frontal sinus were encountered in the human patient (16), care would need to be exercised in order to avoid introduction of mucosa intradurally. Following a procedure in which the frontal sinus is entered, one would need to insure that the sinus is stripped of its mucosa either with the endoscope through the introduction site or either with transnasal procedures per an otolaryngologist. An attempt at occluding the defect could also be made with soft tissue or bone wax.

Endoscopically, the anterior portion of the corpus callosum can be approached as the anterior cerebral artery and its branches are appreciated and circumvented. Blunt dissection with the tip of the endoscope can then be easily performed by introducing the endoscope into the corpus callosum as bisection continues posteriorly. In an animal model or in human usage, ependymal veins would possibly require coagulation via cautery through the working port of the endoscope. However, we did not encounter any bleeding with our dissections. Microscissors could also be used for dissection. Scope depth can next be estimated by sagittal MRI calculation in humans or as with our cadaveric study (8) by examining the brains after the procedure to see how much of the corpus callosum was transected. The extent of callosotomy is still in determinate although most seizures probably spread through the anterior two-thirds of the corpus callosum (16).

We have found that endoscopic corpus callosotomy via a supraorbital trephination is easily performed in the pig. This technique is simple and without obvious complications in this animal. We would conclude that this method of endoscopic callosotomy could be of value to neurosurgeons that perform callosotomy especially in pediatric patients in which the frontal sinus has yet to form. Theoretical indications would be for children in whom a more minimally invasive application of corpus callosotomy is sought. Contraindications would include pathology of the frontal bone e.g. previous craniofacial surgery with hardware, or intradural pathology such as arteriovenous malformation involving the anterior circulation. As this is an animal study, clinical application of this method in humans is now needed in order to prove its efficacy.

\section{References}

1. Wada J. Anterior $2 / 3$ callosal bisection. Comparative observations in animals and man. In: Engel J (ed). Fundamental Mechanisms of Human Brain Function. New York: Raven Press, 1987, pp 259-266.

2. Beasley NJ, Jones NS. A modification to the brow incision for access to the anterior skull base and paranasal sinuses. J Laryngol Otol 1995; 109: 134136.

3. Dare AO, Landi MK, Lopes DK, Grand W. Eyebrow incision for combined orbital osteotomy and supraorbital minicraniotomy: application to aneurysms of the anterior circulation. J Neurosurg 2001; 95: 714-718.

4. Jho HD. Orbital roof craniotomy via an eyebrow incision: a simplified anterior skull base approach. Minim Invasive Neurosurg 1997; 40: 91-97.

5. Menovsky T, Grotenhuis A, de Vries J, Bartels RH. Endoscope-assisted supraorbital craniotomy for lesions of the interpeduncular fossa. Neurosurgery 1999; 44: 106-112.

6. Cohen AR, Perneczky A, Rodziewicz GS, Gingold SI. Endoscope-assisted craniotomy: approach to the rostral brain stem. Neurosurgery 1995; 36: 1128 1130.

7. Hodaie M, Musharbash A, Otsubo H, et al. Imageguided, frameless stereotactic sectioning of the corpus callosum in children with intractable epilepsy. Pediatr Neurosurg 2001; 34: 286-294.

8. Tubbs RS, Smyth M, Salter EG, Blount JP. Eyebrow 
incision for supraorbital trephination for endoscopic corpus callosotomy: a feasibility study. Child's Nerv System (in press).

9. Van Wagenen W, Herren R. Surgical division of commissural pathways in the corpus callosum: relation to spread of an epileptic attack. Arch Neurol Psychiatry 1940; 40: 740-759.

10. Gates JR, Rosenfeld WE, Maxwell RE, Lyons RE. Response of multiple seizure types to corpus callosum section. Epilepsia 1987; 28: 28-34.

11. Oguni H, Olivier A, Andermann F, Comair J. Anterior callosotomy in the treatment of medically intractable epilepsies: a study of 43 patients with a mean follow-up of 39 months. Ann Neurol 1991; 30: 357-364.

12. Spencer SS, Spencer DD, Sass K, Westerveld
M, Katz A, Mattson R. Anterior, total, and twostage corpus callosum section: differential and incremental seizure responses. Epilepsia 1993; 34: 561-567.

14. Sorenson JM, Wheless JW, Baumgartner JE, et al. Corpus callosotomy for medically intractable seizures. Pediatr Neurosurg 1997; 27: 260-267.

15. Browder J, Kaplan HA. Cerebral Dural Sinuses and Their Tributaries. Springfield, IL: Charles C Thomas, 1976.

16. Streeter GL. The development of the venous sinuses of the dura mater in the human embryo. Am J Anat 1915; 18: 145-178.

17. Tubbs RS, Elton S, Salter G, Blount JP, Grabb PA, Oakes WJ. Superficial surgical landmarks for the frontal sinus. J Neurosurg 2002; 96: 320-322. 